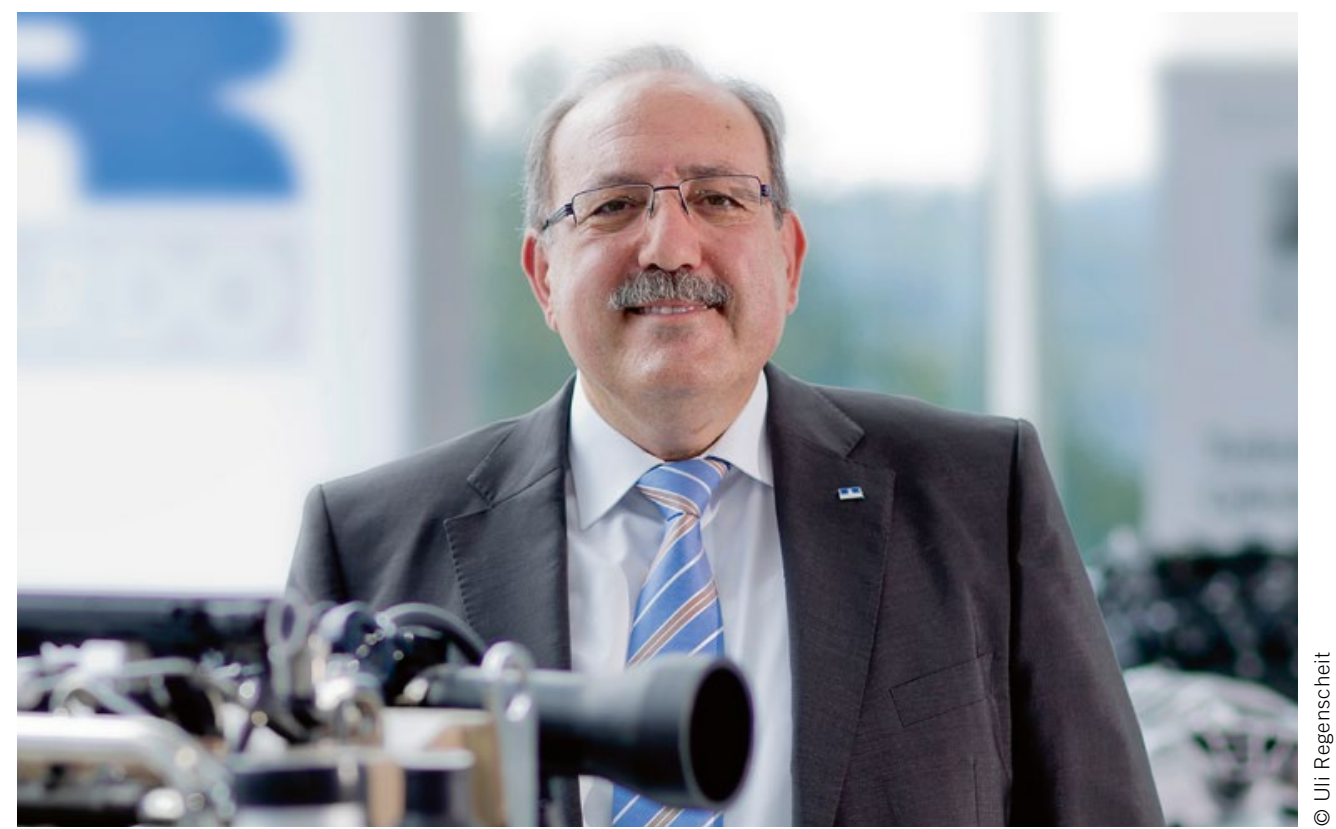

Dr. Ioannis Vlaskos

Bereichsleiter Motorenentwicklung bei Ricardo Deutschland und globaler Leiter des Marktbereichs Marine innerhalb der Ricardo plc.

\title{
Ein neues Kapitel der Motorenentwicklung
}

Die Erfindung des ersten Verbrennungsmotors hat bei den Pionieren jener Zeit ein Feuerwerk an neuen Ideen hervorgebracht. Harry Ricardo war einer davon. Er gründete 1915 sein Unternehmen, weil er die Ergebnisse wissenschaftlicher Forschung der jungen Motorenindustrie zugänglich machen wollte.

So verbesserte beispielsweise die Erfindung des „Turbulent Head“ signifikant die Verbrennung in seitengesteuerten Motoren durch eine Quetschfläche im Zylinderkopf und die dadurch bewirkte Strömung. Dies ermöglichte günstige Motoren auf Basis bereits bestehender Konstruktionen mit akzeptablen Leistungsdaten und Verbrauchswerten. Das war in der ökonomisch schwierigen Zeit nach dem Ersten Weltkrieg von großer Bedeutung für den Fortschritt der Mobilität.

Die Entwicklung von leistungsstarken Motoren für die zivile und militärische Luftfahrt stellte demgegenüber völlig andere Anforderungen. Leistungsdichte und die Fähigkeit zum Betrieb auch in großen Höhen führten zu faszinierenden, aber auch sehr aufwendigen Lösungen. Als Höhepunkt dieser Entwicklung kann der unvollendete Rolls-Royce Crecy bezeichnet werden. Der gleichstromgespülte, schiebergesteuerte Zweitaktmotor mit Direkteinspritzung und höchster Leistungsdichte kam letztlich wegen der schnellen Durchsetzung des Gasturbinen-LuftstrahlTriebwerks in der Flugzeugtechnik nicht mehr zum Einsatz.

Die Weiterentwicklung des Dieselmotors zu kleineren Baugrößen mit akzeptablem Lauf in Bezug auf Geräusch, Rußemission und Rundlauf war eine der drängenden Aufgaben. Von 1931 an und zunächst im Auftrag der Londoner Busgesellschaft entwickelte Ricardo das Wirbelkammer-Brennverfahren, das für „kleine“ Dieselmotoren rußarmen Betrieb und „sanften“ Lauf ermöglichte und in mehreren Generationen bis in die 1980erJahre in Pkw-Dieselmotoren zur Anwendung kam.

In den 1960er-Jahren hielt die Elektronik Einzug in die Kraftfahrzeugtechnik. Einerseits erlaubten computergestützte Berechnungsverfahren nunmehr Vorhersagen über Festigkeit und Schwingungsverhalten von Bauteilen sowie später sogar über die Verbrennung, andererseits wurde die Steuerung und Regelung von Zündung, Gemischbildung und Aufladung der Motoren Zug um Zug auf elektronische Steuergeräte übertragen.

Die Emissionen, insbesondere die des motorisierten Straßenverkehrs, rückten zur selben Zeit in den Vordergrund des öffentlichen Bewusstseins. Dank der Verfeinerung der Sensorik und der elektronischen Steuerung sowie durch Innovationen wie Dreiwegekatalysator, Dieseloxidationskatalysator, Partikelfilter, $\mathrm{NO}_{\mathrm{x}}$-Speicherkat bis hin zum SCR-Verfahren gelang eine Reduzierung der Emissionen auf einen Bruchteil der Emissionswerte der 1960er-Jahre.

Die heute besten Motoren scheinen sich den Grenzen des thermodynamisch Machbaren zu nähern, sofern sie demnächst mit Aggregaten zur Nutzung der Abwärme ausgestattet werden. Doch die Entwicklung ist nicht zu Ende. Ricardo schlägt ein neues Kapitel in der Geschichte des Verbrennungsmotors auf: Neue thermodynamische Kreisprozesse mit quasi innerer Wärmerückführung erscheinen geeignet, die heutigen Grenzen noch weiter hinauszuschieben. Innovation und Pioniergeist bleiben bei Ricardo auch nach hundert Jahren Lebenselixier und treibende Kraft. 